\title{
MicroRNA profiles in various hepatocellular carcinoma cell lines
}

\author{
ASAHIRO MORISHITA ${ }^{1}$, HISAKAZU IWAMA ${ }^{2}$, SHINTARO FUJIHARA ${ }^{1}$, TEPPEI SAKAMOTO ${ }^{1}$, KOJI FUJITA $^{1}$, \\ JOJI TANI ${ }^{1}$, HISAAKI MIYOSHI ${ }^{1}$, HIROHITO YONEYAMA ${ }^{1}$, TAKASHI HIMOTO ${ }^{3}$ and TSUTOMU MASAKI $^{1}$ \\ ${ }^{1}$ Department of Gastroenterology and Neurology; ${ }^{2}$ Life Science Research Center, Kagawa University Faculty of Medicine, \\ Kagawa 761-0793; ${ }^{3}$ Department of Medical Technology, Kagawa Prefectual \\ University of Health Sciences, Kagawa 761-0123, Japan
}

Received May 25, 2015; Accepted May 13, 2016

DOI: $10.3892 / \mathrm{ol} .2016 .4853$

\begin{abstract}
Hepatocellular carcinoma (HCC) is one of the most common causes of cancer-associated mortality worldwide. Although surgery is considered the most effective treatment for patients with HCC, its indication is restricted by limited criteria and a high relapse rate following surgery; therefore, systemic chemotherapy is required for patients with advanced-stage HCC to prolong their survival. MicroRNAs (miRNAs) are endogenous non-coding RNAs of 18-22 nucleotides in length. It has been reported that aberrant expression of miRNAs is a feature shared by various types of human cancer. Previous studies have indicated that the modulation of non-coding RNAs, particularly miRNAs, may be a valuable therapeutic target for HCC. The aim of the present study was to elucidate the miRNA profiles associated with differentiation and hepatitis B virus (HBV) infection observed in HCC cell lines. The human Alex, Hep3B, HepG2, HuH1, HuH7, JHH1, JHH2, JHH5, JHH6, HLE, HLF and Li-7 HCC cell lines were used for an miRNA array. Replicate data were analyzed following their classification into: i) Poorly- and well-differentiated human HCC cells and ii) HBV-positive and -negative human HCC cells. Out of the 1,719 miRNAs, 4 were found to be significantly upregulated and 52 significantly downregulated in the poorly-differentiated cells, as compared with the well-differentiated cells. Conversely, in the HBV-positive cells 125 miRNAs were found to be upregulated and 2 downregulated, as compared with the HBV-negative cells. Unsupervised hierarchical clustering analysis with Pearson's correlation revealed that the miRNA expression levels were clustered both together and separately in each group. In conclusion, miRNA
\end{abstract}

Correspondence to: Dr Asahiro Morishita, Department of Gastroenterology and Neurology, Kagawa University Faculty of Medicine, 1750-1 Ikenobe, Miki-cho, Kida-gun, Kagawa 761-0793, Japan

E-mail: asahiro@med.kagawa-u.ac.jp

Abbreviations: $\mathrm{miR} / \mathrm{miRNA}$, microRNA; HBV, hepatitis virus B; $\mathrm{HCC}$, hepatacellular carcinoma

Key words: hepatocellular carcinoma, microRNA profiles, microRNA array, hepatitis B virus-infected hepatocellular carcinoma, differentiation profile characterization based on various parameters may be a novel approach to determine the etiology of HCC.

\section{Introduction}

Liver cancer is the third most common cause of cancer-associated mortality worldwide, accounting for an estimated $9.2 \%$ of total cancer-associated mortalities in 2008 (1). Surgery is considered the most effective treatment for patients with hepatocellular carcinoma (HCC) (2); however, the indications for surgery are restricted by the size and total number of tumors $(2,3)$. Although the 5-year survival rate of patients with HCC has improved by $>30 \%$ over the past decade, the recurrence rate following surgery is estimated to be nearly $50 \%$ (4); therefore, systemic chemotherapy is required for patients with advanced stages of HCC, in order to prolong their survival.

MicroRNAs (miRNAs) are endogenous non-coding RNAs of 18-22 nucleotides in length $(3,5)$. The effect of miRNAs on the regulation of the expression of various genes is so broad that one miRNA controls >200 genes (6). Aberrant expression of miRNAs is a common feature among various types of human cancer, and has been reportedly associated with patient survival (7-10). Regarding the correlation between miRNAs and HCC, several studies have detected the aberrant expression of specific miRNAs in HCC tissues when compared with normal tissues (11-14). These studies indicated that the modulation of non-coding RNAs, particularly miRNAs, may be a valuable therapeutic target in HCC.

The aim of the present study was to elucidate the miRNA profiles that are associated with differentiation and hepatitis $\mathrm{B}$ virus (HBV) infection observed in HCC cell lines. The characterization of miRNA expression patterns using various parameters may be a novel approach for the treatment of patients with HCC.

\section{Materials and methods}

Cell lines and culture. The Alex, Hep3B, HepG2, HuH1, HuH7, JHH1, JHH2, JHH5, JHH6, HLE, HLF and Li-7 $\mathrm{HCC}$ cell lines were obtained from the Japanese Cancer Research Resources Bank (Tokyo, Japan) and transported to our laboratory. The cell lines were authenticated by the cell bank using short tandem repeat polymerase chain reaction. The cells were grown in minimal essential medium (Gibco; 
Thermo Fisher Scientific Inc., Waltham, MA, USA) supplemented with 10\% fetal bovine serum (catalog no., 533-69545; Wako Pure Chemical Industries, Tokyo, Japan) and penicillin $(10,000$ units/ml)-streptomycin $(10,000 \mu \mathrm{g} / \mathrm{ml})$ (Invitrogen; Thermo Fisher Scientific, Inc., Waltham, MA, USA) in a humidified atmosphere of $5 \% \mathrm{CO}_{2}$ at $37^{\circ} \mathrm{C}$.

Analysis of microRNA array. Total RNA was extracted from the cancer cell lines using a miRNeasy Mini kit (Qiagen, Hilden, Germany), according to the manufacturer's instructions. RNA samples typically showed $\mathrm{A}_{260} \mathrm{O}_{280}$ ratios between 1.9 and 2.1 on an Agilent 2,100 Bioanalyzer (Agilent Technologies, Santa Clara, CA, USA).

Following the measurement of the RNA using an RNA 6,000 Nano kit (Agilent Technologies, Tokyo, Japan), the samples were labeled using a miRCURY Hy3/Hy5 Power Labeling kit (Takara Bio Inc., Tokyo, Japan) and hybridized onto a human miRNA Oligo chip (version 19.0; Toray Industries, Inc., Tokyo, Japan). Scanning was conducted with the 3D-Gene Scanner 3,000 (Toray Industries, Inc., Kusatsu, Japan). 3D-Gene extraction software version 1.2 (Toray Industries, Inc.) was used to read the raw intensity of the image. To determine the change in miRNA expression between poorly- and well-differentiated HCC cell lines or HBV-positive and HBV-negative HCC cell lines, the raw data were analyzed using GeneSpringGX version 10.0 (Agilent Technologies). Samples were first normalized to the 28S RNA and the baseline was then corrected to the median of all samples.

Replicate data were analyzed following their classification into: i) Poorly- and well-differentiated human HCC cells, and ii) HBV-positive and -negative human HCC cells, which were organized by the hierarchical clustering in the GeneSpring software. For the $\log _{2}$ ratios of the miRNA expression intensity between two groups, hierarchical clustering was performed using the furthest neighbor method with the absolute Pearson's correlation coefficient as a metric. The $\log _{2}$ ratios were median-centered across each miRNA in a color-coding of the heat map. The P-value cutoff was set to 0.05 . Only changes of $>50 \%$ in at least one of the time points for each sample were considered significant. All of the analyzed data were scaled by global normalization.

Statistical analysis. All analyses were conducted using the JMP 8.0 software (SAS Institute, Inc., Cary, NC, USA). A paired analysis between the groups was conducted using a Student's $t$ test. $\mathrm{P}<0.05$ was used to indicate statistically significant differences between the groups.

\section{Results}

Differences in miRNA expression between poorly- and well-differentiated human HCC cell lines. Using a custom microarray platform, the expression levels of 1,719 miRNAs were analyzed in various human HCC cell lines. As shown in Fig. 1 and Tables I and II, of the 1,719 miRNAs, 4 were found to be significantly upregulated and 52 were significantly downregulated in the poorly-differentiated cells, as compared with the well-differentiated cells. Unsupervised hierarchical clustering analysis with Pearson's correlation showed that the poorly-differentiated HCC cell lines clustered both together and separately from the well-differentiated HCC cells (Fig. 1).
Table I. Upregulated expression of miRNA in poorly-differentiated $\mathrm{HCC}$ cells, as compared with well-differentiated HCC cells.

\begin{tabular}{lcc}
\hline Upregulated miRNAs & P-values & PD/WD \\
\hline hsa-miR-4498 & 0.026931863 & 2.867818244 \\
hsa-miR-6842-5p & 0.025697328 & 2.461117562 \\
hsa-miR-6800-5p & 0.012943201 & 1.941309698 \\
hsa-miR-4476 & 0.030699533 & 1.759074121 \\
\hline
\end{tabular}

HCC, hepatocellular carcinoma; PD, poorly-differentiated; WD, well-differentiated; miR/miRNA, microRNA.

Differences in miRNA expression between $H B V$-positive and $H B V$-negative HCC lines. To examine the effect of $\mathrm{HBV}$ infection on alterations in miRNAs, miRNA profiles were analyzed in HBV-positive and -negative human HCC cell lines. As shown in Fig. 2 and Tables III and IV, of the 1,719 miRNAs, 125 miRNAs were found to be significantly upregulated and 2 were significantly downregulated in the HBV-positive HCC cells, as compared with the HBV-negative HCC cells. Unsupervised hierarchical clustering analysis with Pearson's correlation showed that the HBV-positive HCC cell lines clustered both together and separately from the HBV-negative HCC cells (Fig. 2).

\section{Discussion}

The aim of the present study was to elucidate the targetable miRNAs associated with the etiology, diagnosis and treatment of HCC. Certain miRNAs, such as miR-26b and miR-132, were found to be downregulated in poorly-differentiated HCC. It has recently been reported that dedifferentiation is involved in the epithelial-mesenchymal transition (EMT), and particularly in the EMT of cancer (15). In order to invade and metastasize to different organs, cancer cells shed their differentiated epithelial phenotype through EMT (15), which suggests that miR-26b or miR-132 may be associated with cancer invasion and metastasis via EMT. In addition, miR-26b has been shown to directly suppress the expression of CDK6 and cyclin E1, resulting in reduced retinoblastoma-associated protein phosphorylation and inhibited cell proliferation (16). miR-132 also inhibits tumor cell proliferation, invasion and migration by targeting Sox 5 (17). These studies also indicated that miR-26b and miR-132 may directly inhibit cancer invasion and metastasis.

In the present study, miR-4476 was upregulated in poorly-differentiated carcinoma. Recently, it has been demonstrated that miR-4476 is one of the top 10 validated miRNA markers differentiating pancreatobiliary cancer from other clinical conditions, including other types of cancer and healthy controls (18). Therefore, this result suggests that advanced stages of HCC, which includes poorly-differentiated cells, induce cholestasis in a similar fashion to pancreatobiliary cancers and may increase the miR-4476 upregulation.

Regarding the effect of HBV, miR-99b was found to be upregulated in HBV-infected HCC cells in the present study. It has been reported that the expression of miR-99b is 


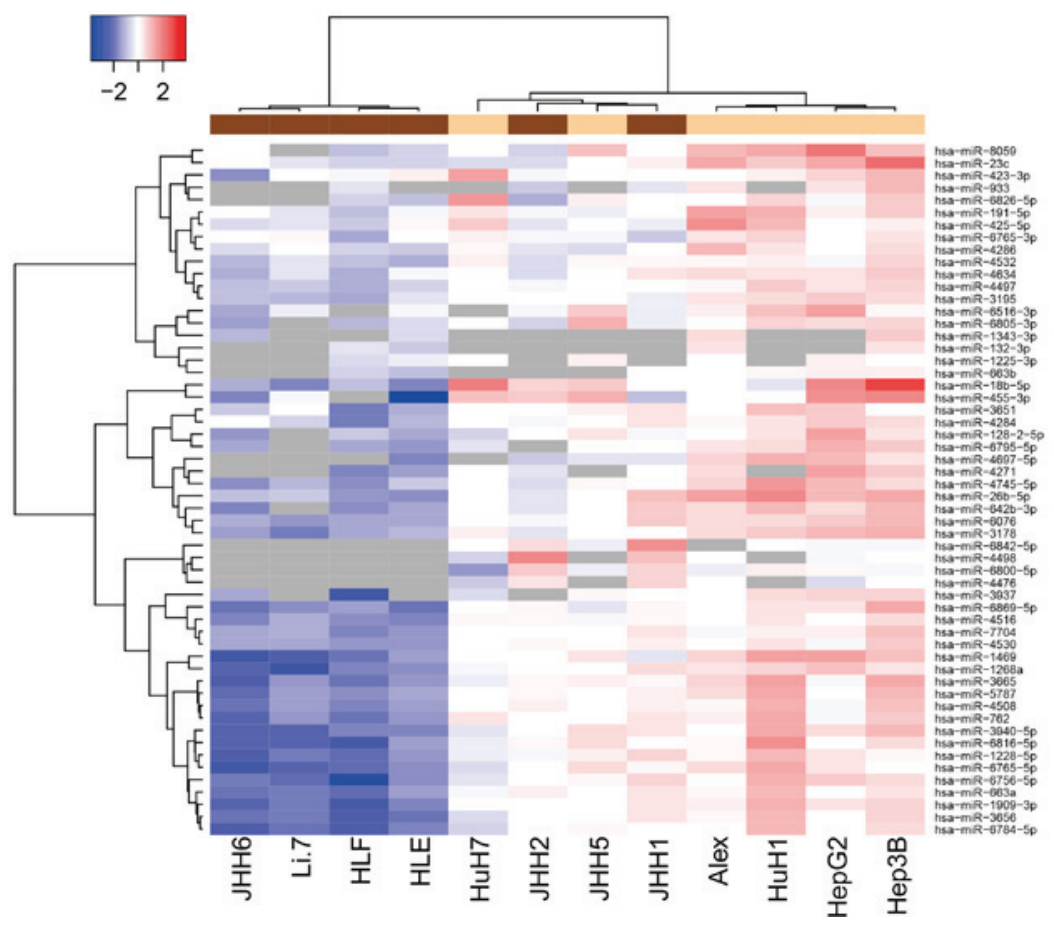

Figure 1. Hierarchical clustering of miRNAs in poorly- and well-differentiated human HCC cell lines. Clustering was performed according to the expression profiles of 56 differentially-expressed miRNAs in poorly- and well-differentiated human HCC cell lines. The columns represent the analyzed samples, while the rows represent the miRNAs. The miRNA clustering tree is shown on the left and the sample clustering tree appears at the top. The color scale shown at the top illustrates the relative expression level of the miRNAs, with red indicating a high expression level and blue indicating a low expression level. miR/miRNA, microRNA; HCC, hepatocellular carcinoma.

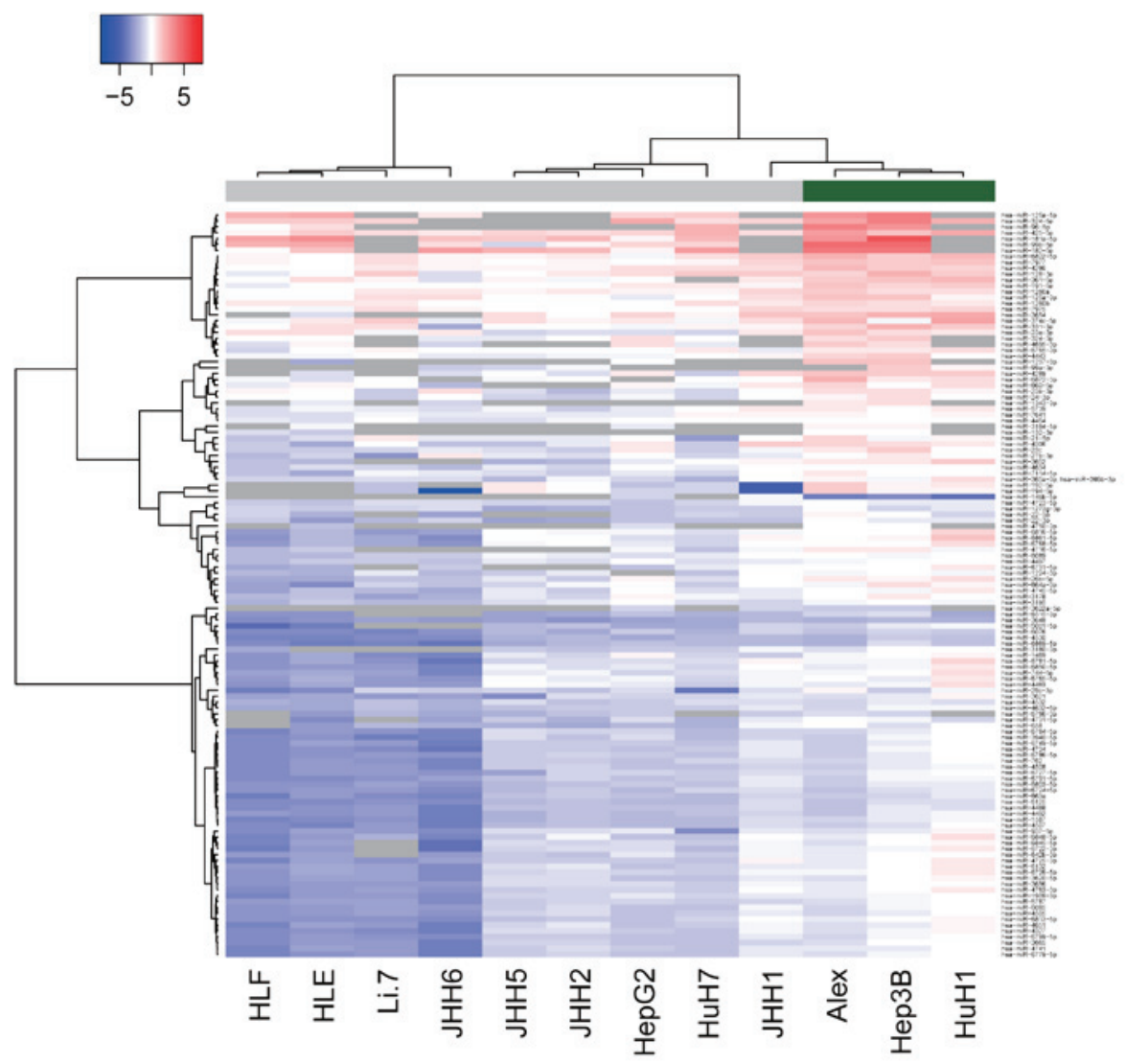

Figure 2. Hierarchical clustering of miRNAs in normal and tumor tissues. Liver tissue clustering was performed according to the expression profiles of 127 differentially-expressed miRNAs in HBV-positive and -negative human HCC cell lines. The columns represent the analyzed samples, while the rows represent the miRNAs. The miRNA clustering tree is shown on the left and the sample clustering tree appears at the top. The color scale shown at the top illustrates the relative expression level of the miRNAs, with red indicating a high expression level and blue indicating a low expression level. miR/miRNA, microRNA; HCC, hepatocellular carcinoma. 
Table II. miRNA downregulation in poorly-differentiated HCC cells as compared with well-differentiated HCC cells.

\begin{tabular}{|c|c|c|}
\hline Downregulated miRNAs & P-value & $\mathrm{PD} / \mathrm{WD}$ \\
\hline hsa-miR-3178 & 0.000974376 & 0.348146401 \\
\hline hsa-miR-1469 & 0.001067111 & 0.256078680 \\
\hline hsa-miR-6805-3p & 0.001867476 & 0.415970562 \\
\hline hsa-miR-3195 & 0.001905223 & 0.508164983 \\
\hline hsa-miR-4497 & 0.002391438 & 0.540368285 \\
\hline hsa-miR-4532 & 0.003797834 & 0.570642150 \\
\hline hsa-miR-4745-5p & 0.005612978 & 0.355402751 \\
\hline hsa-miR-6516-3p & 0.008665895 & 0.446770518 \\
\hline hsa-miR-4634 & 0.009685127 & 0.572465267 \\
\hline hsa-miR-8059 & 0.010182045 & 0.344828448 \\
\hline hsa-miR-3940-5p & 0.010700356 & 0.359070586 \\
\hline hsa-miR-1909-3p & 0.011248665 & 0.401354333 \\
\hline hsa-miR-6795-5p & 0.013039021 & 0.381096482 \\
\hline hsa-miR-132-3p* & 0.014002236 & 0.500476019 \\
\hline hsa-miR-26b-5p* & 0.014113042 & 0.357904962 \\
\hline hsa-miR-6765-5p & 0.014456214 & 0.375871481 \\
\hline hsa-miR-4516 & 0.015208421 & 0.529129777 \\
\hline hsa-miR-1268a & 0.015252062 & 0.430113531 \\
\hline hsa-miR-1225-3p & 0.015675303 & 0.690060509 \\
\hline hsa-miR-191-5p & 0.017084147 & 0.504203776 \\
\hline hsa-miR-5787 & 0.019066417 & 0.426932073 \\
\hline hsa-miR-3665 & 0.019620817 & 0.372159995 \\
\hline hsa-miR-6784-5p & 0.021959677 & 0.423492063 \\
\hline hsa-miR-762 & 0.022064969 & 0.428794025 \\
\hline hsa-miR-425-5p & 0.022167838 & 0.469352798 \\
\hline hsa-miR-6076 & 0.02338926 & 0.489615399 \\
\hline hsa-miR-4284 & 0.025395945 & 0.607050985 \\
\hline hsa-miR-6816-5p & 0.025658929 & 0.342345756 \\
\hline hsa-miR-6756-5p & 0.026680935 & 0.418869876 \\
\hline hsa-miR-6765-3p & 0.028318318 & 0.681942211 \\
\hline hsa-miR-1343-3p & 0.029279009 & 0.369035375 \\
\hline hsa-miR-4697-5p & 0.029348892 & 0.356689006 \\
\hline hsa-miR-4286 & 0.029548705 & 0.606212249 \\
\hline hsa-miR-3656 & 0.029629729 & 0.441205506 \\
\hline hsa-miR-6869-5p & 0.030683568 & 0.450864492 \\
\hline hsa-miR-455-3p & 0.031351866 & 0.340391294 \\
\hline hsa-miR-933 & 0.032763996 & 0.446918418 \\
\hline hsa-miR-3937 & 0.032949412 & 0.428511322 \\
\hline hsa-miR-663b & 0.033189114 & 0.645740828 \\
\hline hsa-miR-1228-5p & 0.034737307 & 0.468155726 \\
\hline hsa-miR-4508 & 0.035873986 & 0.465234100 \\
\hline hsa-miR-23c & 0.038312747 & 0.398936550 \\
\hline hsa-miR-642b-3p & 0.03853801 & 0.474336719 \\
\hline hsa-miR-4530 & 0.03858166 & 0.564198369 \\
\hline hsa-miR-4271 & 0.039079038 & 0.375946014 \\
\hline hsa-miR-18b-5p & 0.046265132 & 0.239201813 \\
\hline hsa-miR-663a & 0.046711854 & 0.497938251 \\
\hline hsa-miR-7704 & 0.046961909 & 0.562374269 \\
\hline hsa-miR-6826-5p & 0.048141645 & 0.450205273 \\
\hline hsa-miR-3651 & 0.048451237 & 0.591375188 \\
\hline hsa-miR-423-3p & 0.04891406 & 0.585477071 \\
\hline hsa-miR-128-2-5p & 0.049142734 & 0.487264349 \\
\hline
\end{tabular}

HCC, hepatocellular carcinoma; miR/miRNA, microRNA; PD, poorly-differentiated; WD, well-differentiated.
Table III. miRNA upregulation in HBV-positive HCC cells as compared with HBV-negative HCC cells.

\begin{tabular}{|c|c|c|}
\hline Upregulated miRNAs & P-value & $\mathrm{HBV}(+) / \mathrm{HBV}(-)$ \\
\hline hsa-miR-99b-5p & 0.000000648 & 9.941304892 \\
\hline hsa-miR-181a-5p & 0.033034307 & 6.386379599 \\
\hline hsa-miR-96-5p & 0.021545231 & 4.758785302 \\
\hline hsa-miR-1237-3p & 0.037257957 & 4.456964302 \\
\hline hsa-miR-182-5p & 0.000177429 & 4.362818593 \\
\hline hsa-miR-125a-5p & 0.005613398 & 3.719262548 \\
\hline hsa-miR-99a-3p & 0.045954557 & 3.494856992 \\
\hline hsa-miR-6861-5p & 0.008595301 & 3.308580171 \\
\hline hsa-miR-6726-5p & 0.002146572 & 3.247738683 \\
\hline hsa-miR-4763-3p & 0.003813145 & 3.075732768 \\
\hline hsa-miR-192-5p & 0.018546977 & 3.068893554 \\
\hline hsa-miR-194-5p & 0.027213074 & 3.058433608 \\
\hline hsa-miR-324-5p & 0.047875781 & 3.025508821 \\
\hline hsa-miR-3665 & 0.000663551 & 3.021045838 \\
\hline hsa-miR-6848-5p & 0.013784248 & 3.003340126 \\
\hline hsa-miR-658 & 0.002645683 & 2.977949153 \\
\hline hsa-miR-3652 & 0.006332146 & 2.969527506 \\
\hline hsa-miR-744-5p & 0.00486586 & 2.967774559 \\
\hline hsa-miR-6132 & 0.00428827 & 2.930151490 \\
\hline hsa-miR-26b-5p & 0.001262254 & 2.924882610 \\
\hline hsa-miR-6872-3p & 0.013248885 & 2.880715544 \\
\hline hsa-miR-6813-5p & 0.008803711 & 2.879469305 \\
\hline hsa-miR-4289 & 0.001809926 & 2.859805967 \\
\hline hsa-miR-3620-5p & 0.004247363 & 2.837639155 \\
\hline hsa-miR-6779-5p & 0.007205138 & 2.789908382 \\
\hline hsa-miR-6799-5p & 0.006060554 & 2.738799039 \\
\hline hsa-miR-1587 & 0.005536711 & 2.737246496 \\
\hline hsa-miR-23c & 0.007181466 & 2.716255574 \\
\hline hsa-miR-4725-3p & 0.026222737 & 2.713962628 \\
\hline hsa-miR-1343-3p & 0.029279009 & 2.709767325 \\
\hline hsa-miR-937-5p & 0.016562749 & 2.704056512 \\
\hline hsa-miR-22-5p & 0.012966623 & 2.690740441 \\
\hline hsa-miR-6816-5p & 0.01716898 & 2.690475807 \\
\hline hsa-miR-6781-5p & 0.043635552 & 2.662786094 \\
\hline hsa-miR-6768-5p & 0.009273849 & 2.658821540 \\
\hline hsa-miR-331-3p & 0.001849624 & 2.656822543 \\
\hline hsa-miR-4327 & 0.021811096 & 2.620193911 \\
\hline hsa-miR-6727-5p & 0.006674229 & 2.597922456 \\
\hline hsa-miR-6722-3p & 0.024746989 & 2.593107400 \\
\hline hsa-miR-5787 & 0.001467763 & 2.579963522 \\
\hline hsa-miR-29c-3p & 0.016910541 & 2.559268566 \\
\hline hsa-miR-22-3p & 0.000110838 & 2.545731351 \\
\hline hsa-miR-3654 & 0.007328507 & 2.536585596 \\
\hline hsa-miR-4507 & 0.013990723 & 2.509463513 \\
\hline hsa-miR-4492 & 0.005952616 & 2.502548594 \\
\hline hsa-miR-4741 & 0.009337902 & 2.486124356 \\
\hline hsa-miR-3621 & 0.015640016 & 2.485247656 \\
\hline hsa-miR-4734 & 0.018933717 & 2.483317331 \\
\hline hsa-miR-6085 & 0.014443652 & 2.479844683 \\
\hline hsa-miR-361-5p & 0.000442472 & 2.474136455 \\
\hline hsa-miR-5001-5p & 0.017579881 & 2.466921307 \\
\hline hsa-miR-6845-5p & 0.018960866 & 2.444791599 \\
\hline hsa-miR-4651 & 0.031451007 & 2.433852833 \\
\hline hsa-miR-664a-3p & 0.022326221 & 2.417433070 \\
\hline hsa-miR-6850-5p & 0.043000995 & 2.410122248 \\
\hline
\end{tabular}


Table III. Continued.

\begin{tabular}{|c|c|c|}
\hline Upregulated miRNAs & P-value & $\operatorname{HBV}(+) / \mathrm{HBV}(-)$ \\
\hline hsa-miR-3940-5p & 0.016650066 & 2.406661676 \\
\hline hsa-miR-4750-3p & 0.034041218 & 2.405803427 \\
\hline hsa-miR-4716-5p & 0.026554669 & 2.368757616 \\
\hline hsa-miR-365a, b-3p & 0.002715735 & 2.366494444 \\
\hline hsa-miR-4508 & 0.007102476 & 2.352557384 \\
\hline hsa-miR-191-5p & 0.000120655 & 2.346171925 \\
\hline hsa-miR-6731-5p & 0.024175847 & 2.333212883 \\
\hline hsa-miR-6822-5p & 0.001204907 & 2.331567699 \\
\hline hsa-miR-4745-5p & 0.015938518 & 2.330093060 \\
\hline hsa-miR-1469 & 0.039665847 & 2.329351564 \\
\hline hsa-miR-762 & 0.010944843 & 2.327308371 \\
\hline hsa-miR-4505 & 0.021004934 & 2.322786379 \\
\hline hsa-miR-3656 & 0.012652065 & 2.316840605 \\
\hline hsa-miR-374c-5p & 0.046201574 & 2.309229277 \\
\hline hsa-miR-4306 & 0.048384309 & 2.306213437 \\
\hline hsa-miR-4463 & 0.043512115 & 2.274070423 \\
\hline hsa-miR-6749-5p & 0.034695635 & 2.258437039 \\
\hline hsa-miR-425-5p & 0.005354369 & 2.258230321 \\
\hline hsa-miR-1909-3p & 0.015268122 & 2.256696389 \\
\hline hsa-miR-4443 & 0.002035551 & 2.247501172 \\
\hline hsa-miR-6784-5p & 0.020580101 & 2.233472310 \\
\hline hsa-miR-6791-5p & 0.025022751 & 2.227203891 \\
\hline hsa-miR-6765-5p & 0.03907315 & 2.196934984 \\
\hline hsa-miR-4695-3p & 0.049035558 & 2.196882473 \\
\hline hsa-miR-4731-5p & 0.026948571 & 2.153748402 \\
\hline hsa-miR-324-3p & 0.008210293 & 2.148721766 \\
\hline hsa-miR-7977 & 0.000154283 & 2.145089801 \\
\hline hsa-miR-3178 & 0.022352 & 2.127295883 \\
\hline hsa-miR-642b-3p & 0.020856928 & 2.086744300 \\
\hline hsa-miR-6786-5p & 0.044762899 & 2.078505858 \\
\hline hsa-miR-6869-5p & 0.038412235 & 2.071725430 \\
\hline hsa-miR-663a & 0.030021104 & 2.045834444 \\
\hline hsa-miR-4488 & 0.028003788 & 2.038574665 \\
\hline hsa-miR-7114-5p & 0.007743122 & 2.030825064 \\
\hline hsa-miR-3180-3p & 0.025916357 & 2.023796991 \\
\hline hsa-miR-6125 & 0.032086556 & 2.008344893 \\
\hline hsa-miR-21-5p & 0.049645958 & 2.003677073 \\
\hline hsa-miR-125a-3p & 0.011495522 & 1.999755015 \\
\hline hsa-miR-4632-5p & 0.009562923 & 1.999301680 \\
\hline hsa-miR-132-3p & 0.014002236 & 1.998097736 \\
\hline hsa-miR-23b-3p & 0.022475719 & 1.997567414 \\
\hline hsa-miR-27b-3p & 0.042591151 & 1.976679667 \\
\hline hsa-miR-6515-3p & 0.043906577 & 1.956257303 \\
\hline hsa-miR-6803-5p & 0.046392317 & 1.928556399 \\
\hline hsa-miR-6724-5p & 0.044214734 & 1.926601244 \\
\hline hsa-miR-4286 & 0.000877998 & 1.922172274 \\
\hline hsa-miR-660-5p & 0.029655234 & 1.920831210 \\
\hline hsa-miR-23a-3p & 0.039960215 & 1.913813878 \\
\hline hsa-miR-1273g-3p & 0.008489419 & 1.887689346 \\
\hline hsa-miR-6076 & 0.046682307 & 1.869956757 \\
\hline hsa-miR-3184-5p & 0.002114973 & 1.859834906 \\
\hline hsa-miR-24-3p & 0.014737629 & 1.853159621 \\
\hline hsa-miR-1224-3p & 0.024802116 & 1.852687602 \\
\hline hsa-miR-128-3p & 0.034442661 & 1.852193951 \\
\hline hsa-miR-5739 & 0.015007524 & 1.813507960 \\
\hline hsa-miR-6766-3p & 0.015357929 & 1.810550072 \\
\hline
\end{tabular}

Table III. Continued.

\begin{tabular}{llc}
\hline Upregulated miRNAs & P-value & HBV $(+) / H B V(-)$ \\
\hline hsa-miR-6089 & 0.01949948 & 1.777100276 \\
hsa-miR-4530 & 0.045923322 & 1.741259423 \\
hsa-miR-4497 & 0.010048462 & 1.733250168 \\
hsa-miR-4634 & 0.011175767 & 1.733040523 \\
hsa-miR-3195 & 0.048689395 & 1.633334528 \\
hsa-miR-4532 & 0.036380915 & 1.573156813 \\
hsa-miR-6765-3p & 0.008380175 & 1.570194232 \\
hsa-miR-3648 & 0.018858947 & 1.557642234 \\
hsa-miR-4723-5p & 0.013307402 & 1.556739349 \\
hsa-miR-1260a & 0.009160577 & 1.550976854 \\
hsa-miR-7641 & 0.040903303 & 1.528537769 \\
hsa-miR-7975 & 0.033849532 & 1.527016010 \\
hsa-miR-1260b & 0.037598062 & 1.399160141 \\
hsa-miR-4454 & 0.044853364 & 1.361601255 \\
\hline
\end{tabular}

HCC, hepatocellular carcinoma; miR/miRNA, microRNA; HBV, hepatitis $\mathrm{B}$ virus.

Table IV. miRNA downregulation in HBV-positive HCC cells as compared with HBV-negative HCC cells.

\begin{tabular}{lcc}
\hline Downregulated miRNAs & P-value & HBV(+)/HBV(-) \\
\hline hsa-miR-146b-5p & 0.012478369 & 0.125399188 \\
hsa-miR-3622a-5p & 0.025065220 & 0.861532186 \\
\hline
\end{tabular}

miR/miRNA, microRNA; HCC, hepatocellular carcinoma; HBV, hepatitis $B$ virus.

associated with the presence of lymph node metastasis (19). In addition, certain miRNAs are associated with the oncogenic processes of HBV-related HCC (3). This data indicates that miRNAs play an important role in the etiology of HBV-related HCC.

In addition, Wang et al (20) demonstrated that 10 upregulated miRNAs (miR-217, miR-518b, miR-517c, miR-520g, miR-519a, miR-522, miR-518e, miR-525-3p, miR-512-3p, and miR-518a-3p) and 11 downregulated miRNAs (miR-138, miR-214, miR-214, miR-199a-5p, miR-433, miR-511, miR-592, miR-483-5p, miR-483-3p, miRNA-708 and miRNA-1275) were identified in $\mathrm{HBV}$-associated $\mathrm{HCC}$ tissues. In the present study, the same microRNAs were not detected in HBV-positive HCC cells; therefore, adjacent normal tissues may be included in the human HCC tissues. These results indicate that the microRNA expression patterns are different from cancer cell lines and cancer tissues. Cell-cell interaction may affect microRNA expression in the microenvironment of cancer tissues.

In conclusion, changes in the regulation of key miRNAs due to differentiation and HBV infection were observed in human HCC cell lines. The present findings suggested that differences in miRNA expression may serve as a novel marker that can aid in elucidating the etiology of human HCC and assist in designing treatments. 


\section{References}

1. Ferlay J, Shin HR, Bray F, Forman D, Mathers C and Parkin DM: Estimates of worldwide burden of cancer in 2008: GLOBOCAN 2008. Int J Cancer 127: 2893-2917, 2010.

2. Małkowski P, Pacholczyk M, Łagiewska B, Adadyński L, Wasiak D, Kwiatkowski A, Chmura A and Czerwiński J: Hepatocellular carcinoma-epidemiology and treatment. Przegl Epidemiol 60: 731-740, 2006.

3. Belghiti J and Kianmanesh R: Surgical treatment of hepatocellular carcinoma. HPB (Oxford) 7: 42-49, 2005.

4. Lee PH, Lin WJ, Tsang YM, Hu RH, Sheu JC, Lai MY, Hsu HC, May W and Lee CS: Clinical management of recurrent hepatocellular carcinoma. Ann Surg 222: 670-676, 1995.

5. Masaki T: MicroRNA and hepatocellular carcinoma. Hepatol Res 39: 751-752, 2009.

6. Krek A, Grün D, Poy MN, Wolf R, Rosenberg L, Epstein EJ, MacMenamin P, da Piedade I, Gunsalus KC, Stoffel M and Rajewsky N: Combinatorial microRNA target predictions. Nat Genet 37: 495-500, 2005.

7. Calin GA, Dumitru CD, Shimizu M, Bichi R, Zupo S, Noch E, Aldler H, Rattan S, Keating M, Rai K, et al: Frequent deletions and down-regulation of micro- RNA genes miR15 and miR16 at 13 q14 in chronic lymphocytic leukemia. Proc Natl Acad Sci USA 99: 15524-15529, 2002.

8. Michael MZ, O' Connor SM, van Holst Pellekaan NG, Young GP and James RJ: Reduced accumulation of specific microRNAs in colorectal neoplasia. Mol Cancer Res 1: 882-891, 2003.

9. Lee EJ, Gusev Y, Jiang J, Nuovo GJ, Lerner MR, Frankel WL, Morgan DL, Postier RG, Brackett DJ and Schmittgen TD Expression profiling identifies microRNA signature in pancreatic cancer. Int J Cancer 120: 1046-1054, 2007.

10. Takamizawa J, Konishi H, Yanagisawa K, Tomida S, Osada H, Endoh H, Harano T, Yatabe Y, Nagino M, Nimura Y, et al: Reduced expression of the let-7 microRNAs in human lung cancers in association with shortened postoperative survival Cancer Res 64: 3753-3756, 2004.
11. Meng F, Henson R, Wehbe-Janek H, Ghoshal K, Jacob ST and Patel T: MicroRNA-21 regulates expression of the PTEN tumor suppressor gene in human hepatocellular cancer. Gastroenterology 133: 647-658, 2007.

12. Gramantieri L, Ferracin M, Fornari F, Veronese A, Sabbioni S, Liu CG, Calin GA, Giovannini C, Ferrazzi E, Grazi GL, et al: Cyclin G1 is a target of miR-122a, a microRNA frequently down-regulated in human hepatocellular carcinoma. Cancer Res 67: 6092-6099, 2007.

13. Wong QW, Lung RW, Law PT, Lai PB, Chan KY, To KF and Wong N: MicroRNA-223 is commonly repressed in hepatocellular carcinoma and potentiates expression of Stathmin1. Gastroenterology 135: 257-269, 2008.

14. Varnholt H, Drebber U, Schulze F, Wedemeyer I, Schirmacher P, Dienes HP and Odenthal M: MicroRNA gene expression profile of hepatitis C virus-associated hepatocellular carcinoma. Hepatology 47: 1223-1232, 2008.

15. LiLand Li W:Epithelial-mesenchymal transition in human cancer: Comprehensive reprogramming of metabolism, epigenetics, and differentiation. Pharmacol Ther 150: 33-46, 2015.

16. Zhu Y, Lu Y, Zhang Q, Liu JJ, Li TJ, Yang JR, Zeng C and Zhuang SM: MicroRNA-26a/b and their host genes cooperate to inhibit the G1/S transition by activating the $\mathrm{pRb}$ protein. Nucleic Acids Res 40: 4615-4625, 2012.

17. Renjie W and Haiqian L: MiR-132, miR-15a and miR-16 synergistically inhibit pituitary tumor cell proliferation, invasion and migration by targeting Sox 5. Cancer Lett 356: 568-578, 2015.

18. Kojima M, Sudo H, Kawauchi J, Takizawa S, Kondou S, Nobumasa $\mathrm{H}$ and Ochiai A: MicroRNA markers for the diagnosis of pancreatic and biliary-tract cancers. PLoS One 10: e0118220, 2015.

19. Feber A, Xi L, Pennathur A, Gooding WE, Bandla S, Wu M, Luketich JD, Godfrey TE and Litle VR: MicroRNA prognostic signature for nodal metastases and survival in esophageal adenocarcinoma. Ann Thorac Surg 91: 1523-1530, 2011.

20. Wang W, Zhao LJ, Tan YX, Ren H and Qi ZT: Identification of deregulated miRNAs and their targets in hepatitis B virus-associated hepatocellular carcinoma. World J Gastroenterol 18: 5442-5453, 2012. 